\title{
THE CHALLENGE AND OPPORTUNITIES OF CROWDSOURCING WEB COMMUNITIES: AN ITALIAN CASE STUDY
}

\author{
Maria Chiara Di Guardo \\ University of Cagliari \\ V.le Sant'Ignazio,17 - 09123 Cagliari, Italy \\ diguardo@unica.it \\ Manuel Castriotta \\ University of Cagliari \\ V.le Sant'Ignazio,17 - 09123 Cagliari, Italy \\ manuelcastriotta@gmail.com
}

\begin{abstract}
The present study explored the impact of a crowdsourcing strategy on the firm's inventive activities. To investigate this area, we drew on an exploratory qualitative case study using a Netnography approach to analyze the open innovation experience and crowdsourcing strategy of a large Italian company in the bakery sector, the Mulino Bianco. This paper has implications for future research on crowdsourcing, particularly regarding the effective use of collective intelligence in the innovation process.
\end{abstract}

Keywords: Open Innovation, Crowdsourcing, Netnography Study

\section{INTRODUCTION}

It is difficult to imagine a more significant topic in today's economy than interorganizational technology. Indeed, there is mounting evidence that points to the fact that a firm's innovation process increasingly involves partners beyond their boundaries, including research organizations, business partners, universities, and customers ${ }^{1}$. The potential benefits that are derived from external sourcing include access to complementary technological resources, faster development of innovations, and improved market access ${ }^{2}$. However, because, in recent years, the concept of "open innovation" has taken center stage in the innovation literature, thanks to recent technologies including many Web 2.0 applications, firms can now use effective tools to integrate customers into the early stages of the innovation process, improve the idea generation phase, and gain a closer proximity to customers ${ }^{3,4,5}$. 
In this vein, crowdsourcing is currently one of the most discussed keywords within the open innovation community ${ }^{6}$. The term crowdsourcing describes a new Web-based business model that harnesses the creative solutions of a distributed network of individuals through what amounts to an open call for proposals ${ }^{7}$. In other words, a company posts a problem online and a vast number of individuals offer solutions to the problem. However the proliferation of such technologies necessitates a deep change on the organization of innovation activities in order to understanding what types of collective intelligence are possible (or not), desirable (or not) and affordable (or not) and under what conditions. As such, the use of collective intelligence to improve the firm innovation process may be simple in concept; however, can be extremely difficult to implement. Indeed, designing the right mechanisms for collective innovation is neither simple nor straightforward and the "rules of engagement" of external knowledge can make an enormous difference in the outcome.

Another basic question regarding mechanism design is people participation and engagement should not to be taken lightly. Indeed, for a large fraction of Web 2.0 projects that have flopped, the primary cause of failure appears to be a lack of engagement. Specifically, participants expect to be treated in a certain way and, more often than not, they want organizers to be engaged as well.

Generally speaking, the performance of many open innovation processes that are based on Web 2.0 applications has been less than optimal for a number of reasons ${ }^{8}$. For one thing, many tools do not provide information on participants, which raises concerns about the accuracy of the output and the possibility that the process might be vulnerable to manipulation. In addition, applications often lack any explicit refereeing process that might provide some degree of quality assurance.

Therefore, these researchers took on this challenge and explored the impact of a crowdsourcing strategy on firms' inventive activities. To investigate this area, we drew on an exploratory qualitative case study using a Netnography approach (a method specifically designed to study cultures and communities online ${ }^{9,10}$ ) to analyze the open innovation experience and crowdsourcing strategy of a large Italian company in the bakery sector, the Mulino Bianco, which is part of the Barilla spa group.

The paper is organized as follows. First, we provide an overview of the rising importance of the open innovation phenomenon and describe the possible forms of purposive inflows of knowledge that characterize open innovation and strategy. Section 3 introduces the case and methods used. Section 4 provides an analysis of how the process of open innovation took place. Based on this analysis, some critical reflections are offered. 


\section{OPEN INNOVATION AND CROWDSOURCING}

Chesbrough suggested that firms have actually moved toward a new paradigm: the "open innovation" model ${ }^{1}$. This model is antithetic to the old paradigm where successful innovation was related to control and internal $\mathrm{R} \& \mathrm{D}$ activities lead to fully internally developed products. Conversely, in the open innovation paradigm, firms can and should use internal and external ideas during the innovation process. Within this context, possible explanations for the increasing importance of external sourcing of technology can be found both on the supply and demand side. The former is characterized by a scientific knowledge that is growing at an incredible pace in almost all major disciplines. This phenomenon is creating new sources of innovation that are available for tapping interested parties, often in seemingly unrelated fields ${ }^{11}$. Further, markets for technologies are emerging and developing in several industries ${ }^{12}$ and, last but not least, is the ever-increasing pool of displaced talent that has resulted from re-engineering and downsizing. The demand side shows a higher competition and growing pressure on costs that requires a faster development cycle $^{13}$, increasing complexity, and multidisciplinarily use of resources required for innovation coupled with the necessity of being responsive to local and global markets (which makes internal development more difficult) ${ }^{14}$, and the search for risk sharing technological policies ${ }^{15}$. All these factors push toward the search for external sources of ideas for innovation.

Moreover, firms will forge linkages to gain access to those capabilities that they perceive will lead to an improved competitive position and a greater chance of mitigating competitive uncertainty ${ }^{16}$.

In addition, customer and user integration into innovation activities is a mode of value creation. Firms gather ideas for innovation from customers and users by integrating them into the early stages of the innovation process. Further, the ideas expressed by customers reflect their needs and wishes and have been described as "need information." Customers also express ideas that have been called "solution information," which represents, not only need information, but also customer-based suggestions that describe how ideas can be transferred into marketable products. With the help of Internet Toolkits and Web 2.0, customers are being asked to design concepts for new products via Internet-based or stand-alone software applications on self-reliance ${ }^{17}$. The basic design rationale captured in the term Web 2.0 is the notion that the web should be used to buttress connections between individuals and provide them unfettered opportunities to express themselves, rather than attempt to curate all possible combinations of knowledge resources or attempt to censor individual contributions. 
Although the literature has paid some attention to the factors that influence the adoption of different innovation activities, relatively little empirical work has addressed the performance implication of these decisions. Arguments that emphasize the benefits of external acquisition assume that many critical capabilities reside outside the boundaries of the firm and appropriation problems are minimal. In these settings, performance is directly tied to the ability to identify, isolate, and solve a specific set of independent technical problems ${ }^{18}$. The concept of absorptive capacity enriches the picture, which suggests that the impact of internal and external knowledge on firm performance is not independent. Further, a firm's ability to profit from external know-how is largely a function of the firm's level of prior related knowledge ${ }^{19}$.

More specifically, while some studies have explored, directly, the effects of a specific innovation activity on innovation performance ${ }^{20}$, recent studies have also provided mounting evidence on the potential for combining internal and external sourcing modes as complementary innovation activities ${ }^{12,15}$.

Crowdsourcing can be explained via a theory of crowd wisdom and an exercise of collective intelligence. Specifically, this model is capable of aggregating talent and leveraging ingenuity, while reducing the costs and time formerly needed to solve problems and increase creativity. Finally, crowdsourcing is enabled only through the technology of the web, which is a creative mode of user interactivity, not merely a medium between messages and people ${ }^{21}$.

Howe examined three crowdsourcing models: contest, collaborative, and moderated. In the contest model, individuals submit ideas and the winner is selected by the company. In the collaborative model, the crowd evolves ideas and picks the winners. In this way ideas evolve and community engagement increase; however, the model is more difficult to manage and control decreases. Finally, in the moderated model, individuals submit ideas, the crowd evolves the ideas, a panel selects the finalists, and the crowd votes on the winners ${ }^{7}$.

Overall it is clear that it is not possible to draw unconditional lessons on the impact of open innovation and crowdsourcing strategies on performance. The value created by these strategies is contingent on the situation, which differs across performance dimensions. Actually, it may even appear that opening the boundaries of innovation has a negative impact on performance. However, shifting the boundaries of $R \& D$ can bring about important efficiency gains in the production of knowledge by providing access to complementary knowledge, assets, and capabilities. This is particularly the case when knowledge grafting is coupled with internal R\&D 
activities. To analyze these seemingly contradicting observations, this paper highlights the need to consider the balance between different strategic objectives and explore, thought the use of a case study, the impact of crowdsourcing on a firm's performance inventive activities.

\section{THE CASE OF MULINO BIANCO}

\subsection{Research Method}

This research was based on an in-depth, inductive netnography case study of the Mulino Bianco. A netnography approach, or online ethnography, refers to a number of related online research methods that adapt to the study of communities and cultures that are created via computer-mediated social interactions ${ }^{9}, 10$. The qualitative data for our netnography analysis was obtained from a selected online community, the "Mulino che vorrei" website. The netnography approach for this case study was purely observational, in which the researchers were specialized types of lurkers ${ }^{10}$.

Given the open-ended nature of our questions regarding the impact of crowdsourcing on the firm's performance inventive activities, we felt that this approach would be most useful for theory building ${ }^{22,23,24}$. Moreover, the netnography case study is an appropriate method of empirical inquiry when the phenomenon to be studied cannot be easily separated from its organizational context $\mathrm{t}^{24}$.

\subsection{The Company}

Mulino Bianco is a part of the Italian Barilla S.p.a. portfolio brand and produces a wide variety of bakery products and Barilla is a world leader in the pasta market. The Barilla group employs 16,000 people and, in 2008, had issued invoices for more than 4.5 billion $€$. At the time of this study, the firm had 26 factories, including a macaroni factory, flour mills, and bake houses. The R\&D department took advantage of 250 researchers who were employed in six branches based in Italy, USA, Russia, France, Germany, Sweden.

\subsection{The Crowdsourcing Strategy}

Mulino Bianco structured its virtual communication via the application of innovative marketing techniques. This strategy provided an institutional website showcase that links to two sites that also are brand products (Pan di Stelle and Grancereale) and an area called "Il tuo Mulino" (Your mill) where there are blogs of surprises, the "tour of the mill," and the "tour of spikes" over the area committed to the community "Nel mulino che vorrei" (In the mill I would like). The whole communication tool makes use of the typical paradigm Web 2.0. 
The corporate website (www.mulinobianco.it) is user-friendly and the target audience consists mainly of mothers in their 30s and 40s. The strategy is to diversify and involve high segmentation and strategic positioning in the market of handicraft, healthy, wholesome, and uncontaminated products. In addition, the innovation strategy aims at generating new products and packaging and the website consists of sections of traditional communication that describes the history, products, promotions, and events, and shows the brand's attention to product sustainability. Such communication is vertical and no instruments relate to content sharing, this is a typical example of a showcase-site 1.0 era.

\subsubsection{The "Pan di Stelle" Web-Site}

On the home page of the Barilla website is a direct link to the whole range of "Pan di stelle" (Star loaf) products, which become the brand. The product line includes cereal biscuits, snacks, and cakes. The layout of this site is particularly interesting from a crowdsourcing standpoint; additionally, standard sections show traditional products. Further, Mulino Bianco joins a blog that discusses new products from the company and what is available on the market; this tool is highly interactive with two sections and a third that makes wide use of 2.0 tools. The most interesting section is called "Stellario;" this project involves the observation of all customer contributions where one can see the STARS IN THE SPONGE on the web. The page opens with the image of a virtual universe where stars represent various contributions of video, audio, and text formats that have been uploaded by customers. Moreover, in the video section, characteristics are related to the democratizing innovation; in particular, there are contributions that describe and show how to prepare new recipes and how to use the sponge stars to prepare for DIY gifts.

\subsection{The Community "The flour Mill I Would Like"}

Mulino Bianco would like to adopt an open innovation approach through the use of the typical paradigm Web 2.0. In particular the project "Il Mulino che vorrei (The flour mill I would like)" is part of an open innovation strategy that is linked to an outside-in process. The community was founded on March $8^{\text {th }}, 2009$ and is an example of a co-generation project and crowdsourcing, which is a workshop that is open to everybody and enables people to get in touch with the "Mulino Bianco" world, propose ideas, and vote for the most original one. The community represents a change of communication model, previously implemented by Mulino Bianco, that aims to not confine consumers to viewers as passive prospects, but to make them active participants who are able to enrich the world of references of the brand with their ideas, experiences, emotions, and conversations ${ }^{8}$. 
The site is divided into five areas: 1) discover the project, 2) propose an idea, 3) rate other people's ideas, 4) see ideas in an assessment, and 5) read the blog. The community aims to collect ideas, analyze the ideas, and actualize them if they are consistent with the company's mission, vision, and values. The management says that it is ready to take into consideration any proposal, whether or not it is related with any current offer. Further, transparency is the basis of this participatory project and all ideas are evaluated and receive a public response of viability or not, with the reasons explaining what helped in making the choice.

When proposing an idea, a customer must be a member of the Mulino Bianco community. After the first filter of audience satisfaction, the ten most voted ideas are collected in a dedicated area and submitted by careful analysis for feasibility. If the outcome is positive, Mulino Bianco commits to introduce the new product in the market; otherwise, the company will provide a public explanation for why the idea did not win. The "View assessment ideas" includes the ten best ideas and the level of assessment. At the end of this process, ideas can be either stored or put on the market. Community members can also contribute via three types of behavior; first, with new ideas; second, by voting; and third, via comments.

At the time of its launch, the web site had 130,000 registered users, of which $75 \%$ were women, mostly mothers 34 years or age. According to Alexa.com, the site had seen a decrease in its ranking over the past eight months from position number 324,198 to position 762,365 and was position 30,553 in Italy. The number of page views increased by $13 \%$ with an increase in the ratio of page views and users by $6 \%$. There was a decrease by $16 \%$ in the average time spent on the site. The community recorded 448 hits and 1,498 page views daily. Mulino Bianco adopted a very powerful viral marketing strategy as demonstrated by data of the contributions in the main social media networks.

A survey conducted within Facebook showed that the keyword "Nel Mulino che vorrei" (In The Flour Mill I would like) generated about 270 results (see Tab. 1). Firstly Mulino Bianco presented an official page with a wide range of links to the institutional website. This page included about 30.769 fans. In addition research showed that about 115 results were composed by groups and fan pages and 155 were composed by "mashup." Internet web 2.0 tools allow customers to change and modify slogans, videos, pictures or to create new ones. In short, "Mashupping" could contribute to an increase in an advertising campaign's reputation and success. In fact this phenomenon involved about 60,000 fans and represented $60 \%$ of the total of results. Therefore, companies must take this activity into account to improve strategy awareness. 
A Youtube.com analysis showed the presence of 97 video with the keyword "The flour Mill I would like" including 29 official and 58 entered by users divided equally between institutional video for commercials and mashups of different natures both comic and satiric, but also typical protests to the brand. Videos were displayed about 130,000 times with 60,000 views that referred to official youtube channels.

In other social media, communication strategies seemed less effective. On Flickr, there were about 139 results with the keyword (Nel Mulino che vorrei), while about 1,840 with the keyword "Mulino Bianco."

Overall, and considering the nature of circularity of communication on social media, it could be concluded that the community generated a significant level of engagement between actual and potential consumers and customers.

Table 1. Social media communication data

\begin{tabular}{cccc}
\hline Social Media & Search results & Members or viewers & Mash-up \\
\hline Facebook & 270 & 30769 & 155 \\
Twitter & 516 & 1427 & 27 \\
Youtube & 97 & 59815 & 58 \\
Flickr & 139 & 1039 & 16 \\
Slideshare & 4 & 1 & 1 \\
\hline
\end{tabular}

Regarding the qualitative analysis of efficiency, the community proposed 3,846 ideas, 5,382 comments, and 52,707 votes. The proposals were made mainly for new products (2,272 proposal ideas; $59.7 \%)$ followed by promotions ( 860 ideas; $22.3 \%$ ), packaging (431 ideas; $11.2 \%$ ) and finally social and environmental commitments (283 ideas; $7.3 \%$ ). Interestingly, the analysis of historical trends showed that the proportion of contributions remained constant.

The hypothesis was that this trend would highlight a high consistency in the desires of community members and, for this reason, a potential index with which to direct management's strategic choices about communication to the target areas. In any case, the most relevant aspects about community contributions was that, currently, no idea had been launched in the market; however, six had been stored.

\section{DISCUSSION AND CONCLUSION}

From our analysis, we believe that the business model, adopted by Mulino Bianco, is currently not particularly effective in creating innovative new products; however, is valid in the analysis of consumer needs and wants. 
In particular, there are some strategic choices that could explain the apparent inefficiency of the innovation process of the community. The hypothesis was that Mulino Bianco is not properly adopting the open innovation and crowdsourcing strategies:

a) It appears to be a questionable choice of non-payment for the best ideas. There is no evidence in the literature about voluntary contributions of high quality, if not for ethical purposes other than the profit of Mulino Bianco. This choice was probably suggest as designers, marketing experts and psychologists, chemists and fans of food and beverage that could make better contributions to the creation of new products, new packaging and, above all, new promotions. In this case, the feedback of consumers would continue to work through the voting system.

b) The model does not provide models of democratizing innovation such as tutorials, training, and software to facilitate and improve the quality of the contributions of community members ${ }^{8}$

c) The lack of such instruments, associated with non-remuneration, does not seem to exploit some of the main reasons analyzed in the process of crowdsourcing such as competition, learning new skills, and fostering a better reputation. (e.g., the phenomenon of open source as Crowdsourcing first experiment). For example, some competitors have implemented strategies for the implementation of some software to create shapes or create new recipes and new ingredients.

d) Mulino Bianco seems to focus more on intrinsic motivation that is based on belonging to a community. The site seems to maintain a high level of involvement and participation as is demonstrated by the statistics.

Another interesting aspect is communication between members. In the community, a member can communicate only by indirectly commenting on other people's posts. These links do not seem particularly effective or helpful in maintaining the diversity of contributions by consumers. The observation was not of any evidence regarding possible innovation strategies based on the resolution of issues such as open source. These dynamics will increase the pace of innovation and are not proposed by management, which instead focuses on the moment, which is essentially generative and offers a common path.

e) The choice not to reward contributors appears more questionable in light of the management of intellectual property of Mulino Bianco. The community elects to retain full rights to all content that is generated within states without establishing motivations that lead to behaviors typical of gift economies ${ }^{25}$. 
f) Not all ideas are published; therefore, it is plausible that, among them, are hidden proposals. The role of censorship and filter seems very strong and reduces the transparency of the project. However, it the project followed the community assessment model, it would be more efficient and reliable.

These researchers found that the quality of proposals were middle class and the business model does not fully exploit some features of open innovation to see causes that could explain inefficiencies of the community regarding the launch of the proposals; specifically, the best hypothesis seems to be a problem with the corporate culture.

The structure of the process of research and development was hierarchical and vertical. Patterns of communication, within the site reference showed, a typical closed innovation R\&D process. In describing these strategies, the company does not make reference to some of the main external resources that are typical of open innovation strategies, such as suppliers, partners, consultants, competitors, and most consumers that are part of the "Crowd" and part of the external environment ${ }^{26}$.

Again, according to some interviews, management is still tied to the logic of closed-innovation that could justify such a gap between the benchmark nearest Starbucks and Mulino Bianco at the time of the market launch of a product.

In these interviews, the CEO and marketing director argued that the objective of the platform is not recruiting industry experts and enthusiasts within the group because researchers are already valid. In substance, it is the latter claim that might explain why Mulino Bianco launches products that are generated by members of their community.

The literature also highlights how the principles of corporate culture, such as "The best researchers work for us," imply the presence of "not invented here syndrome" at the base of closed innovation that could unknowingly block product launched in the market. For example, Starbucks, despite it being a competitor, has launched almost 82 products (in 24 months, the same period of time Mulino Bianco assumed they needed to launch a new product in the market), which directly resulted from its community of co-creation. The statements from the foregoing points have not been challenged by the statements of project managers who have argued that food products may also be required 24 months before launch. The likes of Starbucks-type competitors show the contrary and, in any case, three of the four areas of interest of any proposed community input are not related to food production. Indeed, new packaging, promotions, and changes in social engagement have already been launched in the market. On the contrary from Starbucks, the Mulino Bianco's waiting before launching a new product 
seems to discourage and generate divergence, between members of the community as they do not see tangible results to their contributions. Further, there appears to be an imbalance among the participation of customers in the community and feedback from the Company, which has not actually issued any suggested product in the market.

On the May 6, 2010, the marketing director announced that it is considering an idea from the community but that was not among the ten most voted ones. This attitudeseems to go against the spirit that is seen in the horizontal sharing basis and community's major strength of the Mulino Bianco's blog. This could ultimately lead to a lack of reliability and trustworthiness that could keep customers away from further helping the company.

In conclusion, the Mulino Bianco branch of Barilla appears to be a market-focused company, the only one on the Italian market regarding snacks and biscuits that asks customers their opinions on products and strategies. Mulino Bianco is, more precisely, the only one company following the market, as its competitors only follow a product-driven approach to the market.

Mulino Bianco is far ahead of its competitors in structuring a market-focused approach to consumers as customers seem to appreciate the direction the company has taken, which is underlined by the web-presence of users and by the cooperation in developing a B2C approach to the market with a two-way communication in which basic feedback from the consumer valued, taken into consideration, and adopted to production.

What seems to lack in the Mulino Bianco company, is a costumer-centered approach and, in its crowdsourcing strategy, is the fact that the company does not actualize any of its customers' proposals, even though the sample was consistent. Moreover, promoting itself as a market-driven company and having all rights of input from its target audience, the company seems to operate as a product-oriented company, leaving all business decisions based on the mere management perception and intuition of the market.

\section{REFERENCES}

[1] H.W. Chesbrough, Open innovation: The new imperative for creating and profiting from technology. Boston: Harvard Business School Press Books, 2003.

[2] J. Hagedoorn, Understanding the rationale of strategic technology partnering: Interorganizational modes of cooperation and sectoral 
differences. Strategic Management Journal, 14(5), p 371-385, 1993. http://dx.doi.org/10.1002/smj.4250140505.

[3] E. Von Hippel, and G. Von Krogh, Open source software and the 'private-collective' innovation model: Issues for organization science. Organization Science, 14(2), p209-223, 2003. http://dx.doi.org/10.2139/ssrn.1410789.

[4] E. Carmel, Building your information systems from the other side of the world: How infosys manages time zone differences. MISQ Executive, 5(1), p43-53, 2008.

[5] E. Carmel, and R. Agarwal, Tactical approaches for alleviating distance in global software development. IEEE Software, 18(2), p22-29, 2001. http://dx.doi.org/10.1109/52.914734.

[6] E. Carmel, and P. Tjia, Offshoring information technology: Sourcing and outsourcing to a global workforce. Cambridge, NY: Cambridge University Press, 2005. http://dx.doi.org/10.1017/CBO9780511541193.

[7] J. Howe, Crowdsourcing: Why the power of the crowd is driving the future of business. New York: Crown Business, 2009.

[8] L. Dahlander, and M.G.., Magnusson, Relationships between open source software companies and communities: Observations from nordic firms. Research Policy, 34(4), p481-493, 2005. http://dx.doi.org/10.1016/j.respol.2005.02.003.

[9] R.V. Kozinets, On netnography: Initial reflections on consumer research investigations of cyberculture. Advances in Consumer Research, 25, p366-371, 1998.

[10] R.V. Kozinets, Netnography. Doing ethnographic research online. Thousand Oaks. CA: Sage Publications, 2010.

[11] S.H. Chatterjee, J.J. Freyd, and M. Shiffrar, Configural processing in the perception of apparent biological motion. Journal of Experimental Psycology: Human Perception and Performance, 22(4), p916-929, 1996.

[12] A. Arora, and A. Gambardella, Complementarity and external linkages: The strategies of the large firms in Biotechnology. Journal of Industrial Economics, 38(4), p361-379, 1990. http://dx.doi.org/10.2307/2098345.

[13] M. Iansiti, Shooting the rapids: Managing product development in turbulent environments. California Management Review, 38(1), p37-58, 1995. http://dx.doi.org/10.2307/41165820.

[14] A. Bartlett, and S. Goshal, What is a global manager. Harvard Business Review, 81(8), p101-108, 141, 2003. http://dx.doi.org/10.1002/smj.4250120903.

[15] R. Veugelers, Internal R\&D expenditures and external technology sourcing. Research Policy, 26(3), p303-315, 1997. http://dx.doi.org/10.1016/S0048-7333(97)00019-X. 
[16] N. Nohria, and F. Garcia-Pont, Global Strategic linkages and industry structure. Strategic Management Journal, 12 (S1), p105-124, 1991. http://dx.doi.org/10.1002/smj.4250120909.

[17] E. Bonabeau, Decisions 2.0: The power of collective intelligence, MIT Sloan Management Review, 50(2), p45-52, 2009.

[18] J. De la Mothe, and A.N. Link, Networks, alliances, and partnerships in the innovation process. Boston: Kluwer Academic, 2002.

[19] W. Cohen, and D. Levinthal, Absorptive capacity: A new perspective on learning and innovation. Administrative Science Quarterly, 35(1): p128-152, 1990. http://dx.doi.org/10.2307/2393553.

[20] M. Hitt, R. Hoskisson, R. Ireland, and J. Harrison, Effects of acquisitions on R\&D inputs and outputs. Academy of Management Journal, 34(3), p693-706, 1991. http://dx.doi.org/10.2307/256412.

[21] D.C. Brabham, Crowdsourcing as a model for problem solving. Convergence: The International Journal of Research into New Media Technologies, $\quad$ 14(1), p75-90, 2008. http://dx.doi.org/10.1177/1354856507084420.

[22] B.G. Glaser, and A.L. Strauss, The discovery of grounded theory: Strategies for qualitative research. London: Wiedenfeld and Nicholson, 1967.

[23] M.B. Miles, and A.M. Huberman, Qualitative data anzalysis: A sourcebook of new methods. Newbury Park, CA: Sage, 1984.

[24] R.K. Yin, Case study research: Design and methods. Beverly Hills, California: Sage Publications, 1984.

[25] R.G. Fichman, Going beyond the dominant paradigm for information technology innovation research: Emerging concepts and methods. Journal of the Association for Information Systems, 5(8), p314-355, 2004.

[26] B. Cassiman, M.C. Di Guardo, and G. Valentini, Organizing links with science: cooperate or contract? A project level approach. Research Policy, 39(7), p882-892, 2010. http://dx.doi.org/10.1016/j.respol.2010.04.009. 
